\title{
SEQUELAS DE ACIDENTES DE TRÂNSITO E IMPACTOS NA QUALIDADE DE VIDA
}

\section{Jucimara Zacarias Martins Silveira}

Mestre em Psicologia pela Universidade Católica Dom Bosco (UCDB); Docente no curso de Psicologia da Faculdade UNIGRAN Capital, Campo Grande (MS), Brasil.

E-mail: adm.jucimara@gmail.com

\section{José Carlos Souza}

Pós-Doutor em Ciências da Saúde pela Faculdade de Medicina da Universidade de Lisboa, Portugal; Docente no departamento de medicina da Universidade Estadual de Mato Grosso do Sul, Campo Grande (MS), Brasil.
RESUMO: O objetivo deste trabalho foi avaliar a qualidade de vida geral e qualidade de vida relacionada à saúde de indivíduos com sequelas em decorrência de acidentes de trânsito. Foi realizado um estudo exploratório-descritivo e de corte transversal utilizando os instrumentos de avaliação de qualidade de vida: questionários WHOQOL-100, SF-36 e o questionário sociodemográfico, em uma amostra de 100 participantes. Na avaliação do WHOQOL-100, obtevese os escores médios $(>52,91)$ para todos os domínios, exceto para os aspectos espirituais/religião/crenças pessoais $(81,31)$. Já com o SF36 , verificou-se os menores escores para os domínios aspectos físicos $(11,00)$, aspectos emocionais $(31,00)$ e capacidade funcional $(41,35)$, sendo o maior escore para o domínio estado geral de saúde $(76,71)$. Conclui-se que os indivíduos com sequelas de acidente de trânsito apresentam prejuízos à sua percepção da qualidade de vida e o fator espiritual apresenta-se como um aspecto importante para possibilitar uma melhor qualidade de vida.

PALAVRAS-CHAVE: Acidentes de trânsito; Promoção da Saúde; Qualidade de vida.

\section{TRAFFIC ACCIDENT SEQUELAE AND IMPACTS ON LIFE QUALITY}

\begin{abstract}
Current study assesses life quality in general and life quality related to the health of people with sequelae from traffic accidents. The exploratory, descriptive and transversal study employed questionnaires WHOQOL-100, SF-36 and the socio-demographic questionnaire with 100 participants. Evaluation by WHOQOL-100 revealed mean scores $(>52.91)$ for all domains, excepting aspects on spiritual/religion/personal beliefs (81.31). In the case of SF-36, the lowest scores occurred for the physical domain (11.00), emotional aspects (31.00) and functional capacity (41.35), with the highest score for the domain general health state (76.71). Results reveal that subjects with traffic accidents' sequelae have liabilities in their perception of life quality and the spiritual factor is a highly important aspect for a better life quality.
\end{abstract}

KEY WORDS: Life quality; Traffic accidents; Health enhancement.

\section{INTRODUÇÃO}

Para contextualizar o objeto de estudo pesquisado - Qualidade de Vida (QV) e Acidentes de Trânsito (AT) apresenta-se a seguir alguns 
conceitos. O termo "Qualidade de Vida" tem sido muito discutido em várias áreas de conhecimento e trata-se de um tema extremamente abrangente e subjetivo, que pode ser avaliado a partir de critérios objetivos e subjetivos.

A Organização Mundial de Saúde (OMS), por meio do The WHOQOL Group (1995, p. 1404), com a necessidade de criar instrumentos de avaliação e elaborar estudos na área, adotou uma conceituação mais genérica, e a define como:

[...] a percepção do indivíduo de sua posição na vida, no contexto da cultura e do sistema de valores em que vive e em relação aos seus objetivos, expectativas, padrões e preocupações. É um conceito bem abrangente, afetado de maneira complexa pela saúde física, pelo estado psicológico, pelo nível de independência, pelas relações sociais da pessoa e por suas relações com características significativas do ambiente.

Nessa definição, pode-se compreender que o conceito faz uma referência em como o indivíduo percebe os fatores intrínsecos à sua vida. Trata-se de uma percepção subjetiva, com influências dos contextos culturais, sociais e ambientais (FLECK, 2008). Tratase de uma visão com provável contribuição de estudos sociológicos, sem referir as disfunções ou agravos (SEIDL; ZANON, 2004).

Para o The WHOQOL Group, o estudo de QV se baseia em três aspectos: a subjetividade - diz sobre a percepção do indivíduo (FLECK, 2008); sobre a sua própria condição de saúde e de aspectos não-médicos de sua vida (SEIDL; ZANON, 2004); a multidimensionalidade e a bipolaridade. A partir da compreensão desse aspecto da QV, fica claro que esta só pode ser avaliada pela própria pessoa.

$O$ aspecto da multidimensionalidade significa que a QV abrange várias dimensões da vida do indivíduo (FLECK, 2008); trata-se de um reconhecimento dos diferentes aspectos que abrange a vida de uma pessoa (SEIDL; ZANON, 2004) e, na avaliação, é um fator que deve ser considerado. Quanto ao aspecto da bipolaridade - trata-se da presença de elementos positivos e negativos, como dor e a mobilidade (FLECK, 2008).

No Brasil existe uma cultura que valoriza e considera o condutor do automóvel como o único indivíduo de direitos no ambiente do trânsito. Cultura essa voltada para o autoritarismo que não (re)conhece o direito coletivo e vê o automóvel como símbolo de poder e status, ocorrendo o predomínio de força de quem tem o carro maior, melhor e mais potente ou de ações que intimidam os demais condutores (VIECILI, 2003). No entanto, os conflitos no trânsito fazem com que a morbimortalidade por acidentes de trânsito aumente a cada dia, com isso também os óbitos e lesões em decorrência desses.

Existem algumas considerações sobre acidentes de trânsito como "[...] acontecimentos repentinos, inesperados, imprevistos e involuntários, com a conotação de se tratar de eventos que não podem ser evitados [...]" (ROZESTRATEN, 1996, p. 7). Mas, ao serem analisadas as circunstâncias dos acidentes, constata-se que apenas 10\% deles foram inesperados, imprevistos ou involuntários, e 90\% aconteceram em decorrência da falta de prudência, de cuidado e preparo, considerando que muitos desses acidentes ocorrem nas proximidades de placas advertindo sobre potenciais riscos (ROZESTRATEN, 1996). Para este mesmo autor o trânsito é um problema social, cujos participantes têm necessidades distintas, e que em determinado momento os conflitos surgem devido à ambivalência ou contradição no julgamento da situação, que depende da posição que se ocupa no momento, se está como motorista ou como pedestre.

Considerando que, se é um evento alheio à vontade do homem, muitos dos acidentes de trânsito poderiam ser evitados, tendo em vista que a maioria tem a sua causa na negligência e no não cumprimento das normas de circulação nas vias urbanas (BIAVATI; MARTINS, 2007).

O objetivo deste estudo é avaliar a qualidade de vida geral e qualidade de vida relacionada à saúde de indivíduos com sequelas em decorrência de acidentes de trânsito.

\section{METODOLOGIA}

Utilizou-se o método quantitativo, de corte transversal, no qual foi realizado um estudo 
exploratório-descritivo para conhecer as características sociodemográficas e a QV de indivíduos com sequelas de AT. As aplicações dos questionários foram em três clínicas de fisioterapia, todas conveniadas ao Sistema Único de Saúde (SUS). A amostra foi composta por 100 participantes, sendo o processo de amostragem por conveniência e não-probabilística.

Para a coleta de dados utilizou-se os seguintes instrumentos de avaliação: o Questionário Sociodemográfico, Questionário World Health Organization Qualityof Life-100 (WHOQOL-100) e The Medical Outcomes Study-36-item Short-Form Health Survey (SF-36).

Para a análise estatística dos resultados utilizouse os seguintes testes estatísticos: o teste $t$ de Student para as variáveis categóricas em relação aos domínios dos questionários SF-36 e WHOQOL-100, o teste de correlação linear de Pearson para as variáveis contínuas e o teste de análise de variância (ANOVA). Ressalta-se que o nível de significância adotado para os testes estatísticos foi de $5 \%$, ou seja, $p<0,05$.

Ressalta-se que os princípios éticos da pesquisa envolvendo seres humanos foram atendidos, tendo sido o projeto submetido e aprovado (Parecer 048/10) pelo Comitê de Ética em Pesquisa da Universidade Católica Dom Bosco (UCDB) e os participantes assinaram o Termo de Consentimento Livre e Esclarecido.

\section{RESULTADOS}

Constatou-se na amostra a predominância do sexo masculino (66\%); a faixa etária de 18 a 49 anos (86\%) e de 50 a $\geq 70$ anos (14\%); estado civil solteiro (42\%); o grau de instrução ensino médio (52\%), sendo que somente 4\% tinham o nível superior/pós-graduação; 91,66\% com a renda familiar de $\mathrm{R} \$ 501,00$ a $\mathrm{R} \$ 3.000,00$ antes do AT, e 83,51\% com o mesmo valor de renda depois do AT, havendo uma redução de 8,15\%. Este fator pode estar relacionado aos afastamentos das atividades laborais sem remuneração, em casos de indivíduos que não possuem vínculos empregatícios ou pelo fato de o valor recebido durante o auxílio doença ser menor, se comparado ao salário mensal.
Tabela 1. Análise descritiva das variáveis contínuas dos dados sociodemográficos dos participantes com sequelas de AT

\begin{tabular}{lcccccc}
\hline Variável & $\mathbf{n}$ & Média & Dp & Mínimo & Máximo \\
\hline $\begin{array}{l}\text { Idade (anos) } \\
\text { Renda antes }\end{array}$ & 100 & 36,77 & 13,27 & 18,00 & 76,00 \\
$\begin{array}{l}\text { do Acidente } \\
\text { de Trânsito } \\
\text { (R\$) }\end{array}$ & 96 & $1.580,70$ & $1.062,90$ & 0 & $6.000,00$ \\
$\begin{array}{l}\text { Renda após o } \\
\text { Acidente de } \\
\text { Trânsito (R\$) }\end{array}$ & 97 & $1.152,40$ & $1.018,9$ & 0 & $6.000,00$ \\
$\begin{array}{l}\text { Tempo } \\
\text { de lesão/ }\end{array}$ & 100 & 24,79 & 59,25 & 1,94 & 369,97 \\
$\begin{array}{l}\text { acidente } \\
\text { (meses) }\end{array}$ & & & & & \\
$\begin{array}{l}\text { Duração da } \\
\text { internação } \\
\text { (dias) }\end{array}$ & 89 & 16,27 & 18,81 & 1,00 & 120,00 \\
\hline
\end{tabular}

Fonte: Dados da pesquisa.

Conforme a Tabela 1 , na amostra estudada o tempo médio de lesão é de 24,79 meses para indivíduos com uma média de 36,77 anos de idade, com período de internação em média de 16,27 dias, com uma média de $R \$ 1.580,70$ de renda mensal familiar antes do AT e, após, de $\mathrm{R} \$ 1.152,40$. Observa-se insuficiência de renda, considerada baixa para suprir as necessidades básicas de uma família, ainda mais ao se tratar de dispor de recursos para custear os gastos com a recuperação das lesões e tratamentos de reabilitação, bem como de todo o suporte necessário para esse indivíduo, tais como: transporte, medicações, cadeira de rodas, muletas, consultas e sessões necessárias com os profissionais da saúde.

Tabela 2. Escore geral do WHOQOL-100 da amostra estudada, por domínio

\begin{tabular}{l|c|c|c|c|c}
\hline Domínio & $\mathbf{n}$ & Média & $\mathbf{d p}$ & $\mathbf{F}$ & $\boldsymbol{P}$ \\
\hline Físico & 100 & 57,69 & 19,17 & & \\
Psicológico & 100 & 67,05 & 14,00 & & \\
Nível de Independência & 100 & $\mathbf{5 2 , 9 1}$ & 19,60 & & \\
Relações Sociais & 100 & 69,35 & 13,24 & & \\
Meio Ambiente & 100 & 56,76 & 12,09 & & \\
Espirituais & 100 & $\mathbf{8 1 , 3 1}$ & 16,77 & & \\
\hline
\end{tabular}

Fonte: Dados da pesquisa. 
Na Tabela 2 constam os resultados da avaliação do WHOQOL-100 obtidos pela amostra. Os indivíduos com sequelas de AT apresentaram uma pior QV nos domínios de Nível de Independência, Meio Ambiente e Físico, ou seja, percebem a sua QV em meio termo (não tão boa/ não tão ruim) quanto ao Nível de Independência na mobilidade, em atividades da vida cotidiana, dependência de medicações ou de tratamentos e capacidade para o trabalho, e também quanto à segurança física e proteção, ambiente do lar, recursos financeiros, cuidados com a saúde e sociais: disponibilidade e qualidade e nas oportunidades de adquirir novas informações e habilidades.

Observa-se que o domínio do WHOQOL-100 com maior escore foi Aspectos Espirituais/Religião/ Crenças Pessoais (média de 81,31 e desvio padrão 16,77), o que pode significar que as crenças pessoais dão sentido à vida, dão forças para enfrentar as dificuldades e ajudar a entendê-las.

Tabela 3. Escore geral do SF-36 da amostra estudada, por domínio

\begin{tabular}{lcc|c|c|c}
\hline Domínio & n & Média & dp & F & $P$ \\
\hline Capacidade Funcional & 100 & 41,35 & 37,58 & & \\
Aspectos Físicos & 100 & $\mathbf{1 1 , 0 0}$ & 26,43 & & \\
Dor & 100 & 50,01 & 26,18 & & \\
Estado Geral de Saúde & 100 & $\mathbf{7 6 , 7 1}$ & 19,60 & & \\
Vitalidade & 100 & 66,35 & 20,80 & & \\
Aspectos Sociais & 99 & 61,74 & 28,28 & & \\
Aspectos Emocionais & 100 & 31,00 & 40,27 & & \\
Saúde Mental & 100 & 67,92 & 23,24 & & \\
\hline
\end{tabular}

Fonte: Dados da pesquisa.

Fica demonstrado, por meio do SF-36, um comprometimento na QV diante dos domínios Aspectos Físicos, Aspectos Emocionais e Capacidade Funcional. Isso significa que os participantes estão com algum tipo de limitação na quantidade de trabalho, bem como com interferência nas atividades diárias e/ou na produtividade; que há aspectos psicológicos que não estão possibilitando um bem-estar para o indivíduo e a presença de limitações que abrangem a capacidade física, conforme escore geral do SF-36 da amostra estudada na Tabela 3.

\section{DISCUSSÕES}

Quanto aos resultados apresentados sobre o perfil sociodemográfico da amostra nas variáveis de sexo e idade, o encontrado está de acordo com o que a Organização Mundial da Saúde (2004) afirma: que a grande maioria dos indivíduos acidentados no trânsito no mundo inteiro são jovens do sexo masculino, na faixa etária de 15 a 44 anos; e também de acordo com a pesquisa de França et al. (2011), que avaliaram a QV de indivíduos com lesão medular traumática, apresentando uma média de idade de 42,95 anos e com predominância de $91,5 \%$ do sexo masculino e apenas $8,5 \%$ do feminino. Corroboram, também, com este perfil epidemiológico as pesquisas de Ganne (2010), Marín-León (2012) e Bacchieri e Barros (2011).

O predomínio quanto ao sexo nos envolvimentos em AT é visível, sendo mais intenso nos homens. Isso pode estar relacionado à maior exposição, devido ao comportamento social e cultural dessa categoria, estando mais vulneráveis aos riscos de lesões e mortes. Observouse, ainda, que os indivíduos envolvidos em AT são adultos jovens, em fase economicamente ativa, considerando a faixa etária de 20 a 50 anos, que são indivíduos trabalhadores, estando na idade mais produtiva de suas vidas. Em relação aos indivíduos com idade acima de 60 anos, observou-se que o tipo predominante de AT é o atropelamento (ABREU et al., 2010).

Estudos na área apontam que os condutores jovens estão mais vulneráveis ao AT, devido ao fato da falta de experiência e facilidade para atribuir a diversão ao dirigir um veículo, impossibilitando assim a reflexão das consequências do seu comportamento. No que se refere ao estado civil e à escolaridade, verificou-se que os solteiros e com ensino médio são mais frequentes na amostra. Bacchieri e Barros (2012) citam algumas características comportamentais relacionadas à idade e à gravidade dos acidentes de trânsito, tais como: audácia, imaturidade, sensação de invulnerabilidade, tendência de superestimar capacidades e inexperiência na condução, somadas à necessidade de integrar-se ao grupo.

Quanto ao perfil socioeconômico, as características do acidente e intervenção do serviço social na emergência em pacientes vítimas da violência 
no trânsito, conforme Anjos et al. (2007) constataram que $40 \%$ dos condutores de veículos a motor tinham o ensino médio completo e que $35 \%$ dos condutores de motocicletas possuíam o ensino fundamental completo. Dados de outra pesquisa constatam que $54,54 \%$ tinham menos de 8 anos de estudo, e 45,46\% mais de 8 anos de estudos (OLIVEIRA; SOUSA, 2006). Quanto à alteração na renda mensal familiar, fica demonstrado que o AT altera a renda familiar do indivíduo acidentado.

No perfil das lesões, a predominância aconteceu nos membros inferiores, fato relacionado ao tipo de veículo também predominante - a motocicleta. O condutor deste veículo está mais exposto aos acidentes, lesões graves e óbitos. Em alguns casos, observa-se a reincidência em acidentes, principalmente em casos em que os condutores são profissionais que utilizam o trânsito como ambiente de trabalho, como no caso de motoboys e mototaxistas. Soares et al. (2011), em um levantamento para conhecer as características dos acidentes de trânsito ocorridos com motoboys nos municípios de Londrina e Maringá (PR), discutiram sobre a susceptibilidade aos acidentes, a necessidade de estratégias e políticas específicas de prevenção, ressaltando que o envolvimento destes não estão apenas relacionados ao seu comportamento, mas também com as exigências do ambiente e de regras do mercado.

Já quanto às lesões em decorrência ao AT, requerem um tempo relativamente longo de internação. $\mathrm{O}$ indivíduo acidentado pode tornar-se um politraumatizado, com um tempo de permanência hospitalar parecido com o que ocorre nos casos de doenças crônicas (SOUSA FILHO; XAVIER; VIEIRA, 2008).

Quanto à avaliação com o WHOQOL-100, resultados semelhantes foram encontrados na avaliação de QV e a importância dada à espiritualidade/religiosidade/ crenças pessoais em adultos com e sem problemas crônicos de saúde e constatou-se que a presença de uma doença crônica pode ser associada com a piora na maioria dos domínios, exceto o domínio Aspectos Espirituais/ Religião/Crenças Pessoais. Neste estudo, os escores são mais elevados em pessoas doentes (ROCHA; FLECK, 2011); no estudo de QV, em indivíduos com sequelas neurológicas, com o WHOQOL-Breve, demonstrou por meio desta avaliação que essa população apresentou um grau de dependência funcional com a presença de alterações neurológicas que pode acarretar prejuízos na sua percepção de QV e parece que há uma relação muito importante com os aspectos sociais - pessoais, familiares e sociais (BANJA et al., 2012).

No entanto, esses resultados podem representar que o evento AT e as patologias adquiridas através deste são muito limitadoras ao indivíduo, no que diz respeito às atividades diárias, com prejuízos nas ações humanas mais básicas e importantes para o indivíduo: mobilidade, trabalho, saúde, autonomia para atividades cotidianas (vestir-se, tomar banho, comer, entre outras). Agregado a isso, a percepção desse indivíduo quanto à segurança física e proteção pode ter ficado comprometida devido à experiência relacionada ao AT, fato que lhe trouxe prejuízos financeiros e sendo levado a recorrer, na maioria dos casos, aos serviços de saúde e sociais disponibilizados pelo Estado. Nesse contexto, é compreensível e visível a diminuição das oportunidades em adquirir novas informações, habilidades e na participação de atividades de lazer/recreação, podendo evidenciar um impacto na avaliação da QV.

Em relação à correlação entre a espiritualidade e QV, atualmente, já se estudam uma associação da QV a uma variável que é Coping Religioso/Espiritual, ou seja, o uso da espiritualidade, fé ou religião para lidar com o estresse e os problemas da vida; sendo considerado Coping Religioso/Espiritual positivo os que utilizam dessa estratégia de enfrentamento (PANZINI, 2007).

Os indivíduos, através das suas crenças pessoais, interpretam os acontecimentos a partir dessa interpretação dando sentido aos fatos; a espiritualidade entra como algo que lhes promova a esperança, a segurança e perseverança, ou seja, o bem-estar psicológico, resultando assim em uma melhor QV. Tratase de uma característica muito interessante observada na amostra, pois há uma tendência do senso comum em atribuir a causa de um acidente a uma força superior, à maldição, ao castigo divino ou um aprendizado, com um discurso composto de conteúdos mágicos e religiosos: "foi da vontade de Deus", "Deus quis assim", "Deus não me ama, porque tirou o meu filho", "tem coisas que é para a gente aprender" (BIAVATI; MARTINS, 2007; SILVEIRA, 2009). Porém demonstrou-se na presente pesquisa que o fator espiritual foi importante para favorecer uma melhor QV. 
Já para a compreensão dos resultados apresentados no SF-36, as variáveis qualidade do atendimento oferecido pelo sistema de saúde, tipo e gravidade das lesões, número de intervenções cirúrgicas, grau de sequelas, dor, acesso à reabilitação e condições e condição socioeconômica podem influenciar na QV após o trauma (ALVES, 2009). Outro indicador importante no caso de lesões é a presença da dor e das complicações em decorrência ao quadro, apresentando-se como fator muito influenciador para a redução da QV.

Quanto aos aspectos emocionais do indivíduo acidentado, constatou-se em uma pesquisa que os participantes atribuíram as suas ansiedades à demora na recuperação da saúde, ao tratamento hospitalar prolongado, às suspensões de cirurgias e ao retardo para agendá-lo (SOUSA FILHO et al., 2008). Resultados de estudo sobre a $\mathrm{QV}$ em casos de lesão medular traumática concluíram que 55,3\% dos participantes estão insatisfeitos com a QV e que os domínios social e ambiental apresentaram maior correlação com a QV, o que pode estar relacionado ao fato da lesão medular prejudicar, de forma significativa, a capacidade das pessoas para desempenharem várias atividades cotidianas (FRANÇA et al., 2011).

Acredita-se que os resultados obtidos a partir da avaliação do SF-36 podem estar relacionados ao fato de o indivíduo com sequelas de AT, na maioria dos casos, passar por um longo período com algum tipo de limitação física, com a quantidade de trabalho reduzida, devido às dificuldades e interferências nas atividades diárias, bem como as consequências do estado psicológico no bem-estar, que pode ser pelas mudanças abruptas no estilo de vida, provocado pelas lesões. Pereira e Araújo (2005), citado por Brunozi et al. (2011), ressaltaram que o cenário de lesões físicas pode provocar a quebra da unidade psicofísica do indivíduo em decorrência das mudanças no corpo e nas limitações no cotidiano, provocando reações psicológicas, tais como depressão, agressividade, apatia, isolamento, impulsividade.

Entretanto, as lesões por AT e a gravidade do trauma podem determinar o período de internação, tipo de sequelas e a possibilidade ou não de diminuição da capacidade funcional, afastamento das atividades ocupacionais, dependência de medicamentos e tratamentos médicos e prejuízos no convívio social. $\mathrm{Na}$ amostra pesquisada, embora as limitações físicas e a redução na capacidade funcional estejam muito presentes, os indivíduos com sequelas de AT percebem a sua saúde geral como boa, possibilitando assim uma melhor QV.

\section{CONCLUSÃO}

Conclui-se que as sequelas em decorrência de AT comprometem a percepção do indivíduo de suas condições de vida, do seu bem-estar psicológico, com redução na capacidade para o trabalho, e limitações nos aspectos físicos, como consequência, a diminuição da QV. Considerando que o evento AT e as sequelas adquiridas através deste são muito limitadoras ao indivíduo no que diz respeito às atividades diárias mais básicas e importantes como mobilidade, trabalho, saúde e autonomia para as atividades cotidianas (vestir-se, tomar banho, comer, entre outras), observam-se, também, mudanças abruptas no estilo de vida e na saúde devido às lesões.

Os resultados obtidos nesta pesquisa confirmaram a importância dos estudos sobre QV e AT em indivíduos com sequelas, ao ser observado que ocorrem várias mudanças e dificuldades em decorrência do AT e o impacto que estas têm na percepção da QV, como foi comprovado na presente pesquisa. A partir desses resultados, conclui-se que essa população vivencia especificidades importantes, relacionadas às lesões e à QV após o acidente, podendo este estudo ser um norteador para a melhoria da assistência e para fundamentar propostas e programas de prevenção e intervenção na educação, saúde e segurança para o trânsito.

\section{REFERÊNCIAS}

ABREU, I. S. Qualidade de vida relacionada à saúde de pacientes em hemodiálise nomunicípio de Guarapuava - PR. 2005. 97 f. Dissertação (Mestrado em Saúde Pública) - Escola de Enfermagem de Ribeirão Preto, Ribeirão Preto, SP.

ALVES, A. L. A. et al. Qualidade de vida de vítimas de trauma seis meses após a alta hospitalar. Rev Saúde Pública, 
São Paulo, v. 43, n. 1, p. 154-160, 2009. Disponível em: $<$ http://www.scielo.br/pdf/rsp/v43n1/6952.pdf > . Acesso em: 14 fev. 2016.

ANJOS, K. C. et al. Paciente vítima de violência no trânsito: análise do perfil socioeconômico, características do acidente e intervenção do serviço social na emergência. Acta ortop bras., São Paulo, v. 15, n. 5, p. 262-266, 2007. Disponível em: <http://www.scielo.br/pdf/aob/v15n5/ a06v15n5.pdf>. Acesso em: 18 jul. 2016.

ARAÚJO, M. R. M.; OLIVEIRA, J. M.; JESUS, M. S.; SÁ, N. R.; SANTOS, P. A. C.; LIMA, T. C. Transporte Público Coletivo: discutindo acessibilidade, mobilidade e qualidade de vida. Psicol. Soc., v. 3, n. 23, p. 574-582, 2011. Disponível em: < http://www.ufrgs.br/seerpsicsoc/ ojs2/index.php/seerpsicsoc/article/viewFile/3328/1990>. Acesso em: 14 fev. 2016.

BACCHIERI, G.; BARROS, A. J. D. Acidentes de trânsito no Brasil de 1998 a 2010: muitas mudanças e poucos resultados. Rev Saúde Pública, v. 5, n. 45, p. 949-963, 2011. Disponível em: < http://www.scielo.br/pdf/rsp/ v45n5/2981 > . Acesso em: 13 maio 2016.

BANJA, D. H.; TSUKAMORO, H. F.; SILVA, L. F. A.; CAMARGO, N. D. Análise da funcionalidade e da qualidade de vida de pacientes com sequelas neurológicas. Saúde e Pesqui., v. 1, n. 5, p. 49-57, 2012. Disponível em: < http:// periodicos.unicesumar.edu.br/index.php/saudpesq/ article/view/2175 > . Acesso em: 13 maio 2016.

BIAVATI, E.; MARTINS, H. Rota de colisão: a cidade, o trânsito e você. São Paulo: Berlendis \& Vertecch, 2007.

BRUNOZI, A. E.; SILVA, A. C.; GONÇALVES, L. F.; VERONEZI, R. J. B. Qualidade de Vida na lesão medular traumática. Rev Neurociênc, v. 19, n. 1, p. 139-144, 2011. Disponível em: < http://revistaneurociencias.com. br/edicoes/2011/RN1901/revisao/444\%20revisao.pdf > . Acesso em: 13 maio 2016.

FLECK, M. P. A. Problemas conceituais em qualidade de vida. In: FLECK, M. P. A. (Org.). A avaliação de qualidade de vida: guia para profissionais de saúde. Porto Alegre: Artmed, 2008.
FRANÇA, I. S. X.; COURA, A. S.; FRANÇA, E. G.; BASÍLIO, N. N. V.; SOUTO, R. Q. Qualidade de vida de adultos com lesão medular: um estudo com WHOQOL-bref. Rev esc enferm USP, v. 6, n. 45, p. 1364-1371, 2011. Disponível em: <http://www.revistas.usp.br/reeusp/ article/view/40846/0 > . Acesso em: 13 maio 2016.

GANNE, N. Estudo sobre acidentes de trânsito envolvendo motocicletas na Cidade de Corumbá e região, Estado do Mato Grosso do Sul, Brasil, no ano de 2007. Rev PanAmaz Saude, v. 3, n. 1, p. 19-24, 2010. Disponível em: $<$ http://scielo.iec.pa.gov.br/scielo.php?script $=$ sci arttext\&pid=S2176-62232010000300003 > . Acesso em: 13 maio 2016.

MARÍN-LEÓN, L.; BELON, A. P.; BARROS, M. B. A.; ALMEIDA, S. D. M.; RESTITUTTI, M. C. Tendência dos acidentes de trânsito em Campinas, São Paulo, Brasil: importância crescente dos motociclistas. Cad Saúde Pública, Rio de Janeiro, v. 1, n. 28, p. 39-51, 2012. Disponível em: <http://www.scielo.br/pdf/csp/ v28n1/05 > . Acesso em: 13 maio 2016.

OLIVEIRA, N. L. B.; SOUSA, R. M. C. Retorno à atividade produtiva de motociclistas vítimas de acidentes de trânsito. Acta paul enferm., São Paulo, v. 19, n. 3, p. 284-289, 2006. Disponível em: <http://www.scielo.br/ pdf/ape/v19n3/a05v19n3.pdf>. Acesso em: 12 jan. 2011.

PANZINI, R. G. et al. Qualidade de vida e espiritualidade. Rev psiquiatr clín., São Paulo, v. 34, p. 105-115, 2007. Disponível em: <http://www.lume.ufrgs.br/ handle/10183/20617 > . Acesso em: 24 maio 2016.

ROCHA, N. S.; FLECK, M. P. A. Avaliação de qualidade de vida e importância dada a espiritualidade/religiosidade/ crenças pessoais (SRPB) em adultos com e sem problemas crônicos de saúde. Rev psiquiatr clín, São Paulo, v. 38, n. 1, p. 19-23, 2011. Disponível em: < http://www.scielo. br/pdf/rpc/v38n1/a05v38n1.pdf $>$. Acesso em: 24 maio 2015.

ROZESTRATEN, R. J. A. Os sinais de trânsito e o comportamento seguro: manual para compreender os sinais de trânsito e aprender o que deve ser feito na sua presença. 2. ed. Porto Alegre: Sagra Luzzatto, 1996. 
SEIDL, E. M. F.; ZANON, C. L. M. C. Qualidade de vida e saúde: aspectos conceituais e metodológicos. Cad Saúde Pública, Rio de Janeiro, v. 20, n. 2, p. 580-588, 2004. Disponível em: <http://www.scielo.br/pdf/csp/v20n2/27. pdf $>$. Acesso em: 12 jan. 2015.

SOARES, D. F. P. P.; MATHIAS, T. A. F.; SILVA, D. W.; ANDRADE, S. M. Motociclistas de entrega: algumas características dos acidentes de trânsito na Região Sul do Brasil. Rev Bras Epidemiol., v. 14, n. 3, p. 435-444, 2011. Disponível em: <http://www.scielosp.org/pdf/ rbepid/v14n3/08.pdf> . Acesso em: 13 maio 2016.

SOUSA FILHO, O. A.; XAVIER, E. P.; VIEIRA, L. J. E. S. Hospitalização na óptica do acidentado de trânsito e de seu familiar - acompanhante. Rev esc enferm USP, São Paulo, v. 42, n. 3, p. 539-546, 2008. Disponível em: $<$ http://www.scielo.br/pdf/reeusp/v42n3/v42n3a17. pdf $>$. Acesso em: 22 mar. 2015.

SILVEIRA, J. Z. M. O lado oculto dos acidentes de trânsito envolvendo crianças e adolescentes. 2009. 59 f. Trabalho de Conclusão de Curso (Graduação em Psicologia) - Universidade Católica Dom Bosco, Campo Grande, MS.

THE WHOQOL GROUP. The World Health Organization Quality of Life Assessment (WHOQOL): Position paper from the World Health Organization. Soc Sci Med, Oxford, v. 41, n. 10, p. 1.403-1.410, 1995.

VIECILI, J. Ansiedade e comportamento de dirigir. In: HOFFMANN, M. H.; CRUZ, R. M.; ALCHIERI, J. C. (Org.). Comportamento humano no trânsito. São Paulo: Casa do Psicólogo, 2003, p. 359-374.

WORLD HEALTH ORGANIZATION. World reporton road traffic injury preventions summary. Geneva: WHO, 2004 .

Recebido em: 20 de julbo de 2016

Versão final recebida em: 22 de agosto de 2016

Aceito em: 30 de agosto de 2016 